\title{
WACSeries
}

Volume 7, Issue 3 - February 2021

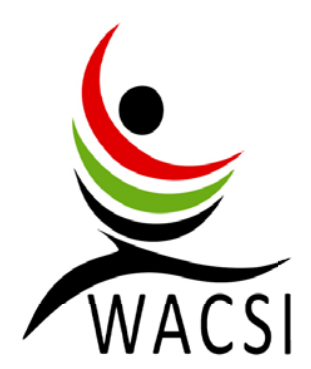

WEST AFRICA CIVIL SOCIETY INSTITUTE

\section{Youth Leadership and Governance in West Africa}
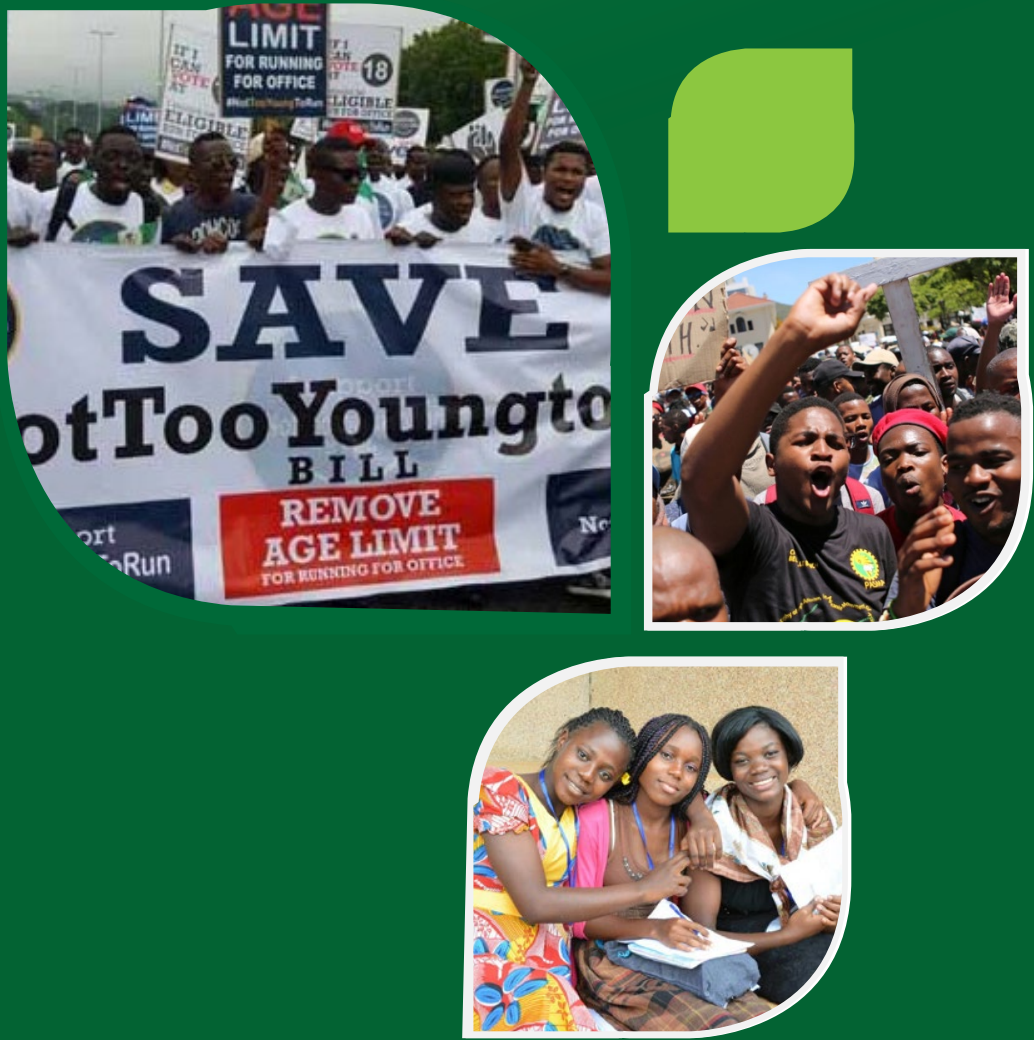

Metolo Foyet 
AUTHOR

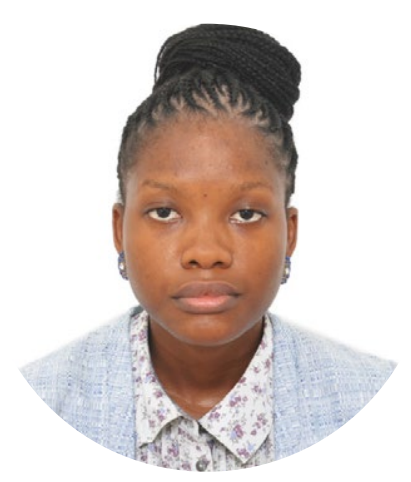

Metolo Foyet, is a politics and security expert, with keen interest in environmental and social safeguards thematic. She is a recipient of the U.S. Department of State's Young African Leaders Initiative (YALI) program, the West African Civil Society Institute (WACSI)'s Next Generation Internship (NGIP) flagship program, the Commonwealth100 Program. She is a member of the Francophone Network of Evaluation (RFE) and the Mandela Institute for Development Studies (MINDS) network. Published author with over hundred publications spread into academic papers, story books, blogs, articles and artworks. She graduated Magna Cum Laude from Lancaster University with a B.A in Politics and International Relations and with Honors from the Kofi Annan International Peacekeeping Training Centre (KAIPTC) with a M.A in Peace, Conflict \& Security. Metolo currently pursues a PhD in Environmental Management and Spatial Planning.

\section{Editorial Team}

Jimm Chick Fomunjong - Head, Knowledge Management Unit, WACSI

Christian Elongué Ngnaoussi - Former Programme Officer, Knowledge Management Unit, WACSI

\section{About WACSI}

The West Africa Civil Society Institute (WACSI) was created by the Open Society Initiative for West Africa (OSIWA) to reinforce the institutional and operational capacities of civil society in the region. WACSI also serves as a resource centre for training, research and documentation, experience sharing and political dialogue for CSOs in West Africa..

www.wacsi.org

\section{About WACSeries}

WACSeries are analytical periodic write-ups on topical themes and issues relevant to West Africa. These write-ups provide experts, researchers and practitioners a space to reflect, analyse and posit views and recommendations on emerging issues and debates. The WACSeries Issue Paper are thought provoking and intellectually engaging write ups that provide critical reflections and analysis of issues relevant to civil society and development in West Africa.

\section{Obectives of WACSeries}

- To raise awareness on key issues in West Africa;

- To generate debates and discussions on these issues;

- To proffer recommendations on civil society involvement in advocacy;

- To provide recommendations to policy makers. 


\title{
inti \\ Youth Leadership and Governance in West Africa
}

\author{
Copyright WACSI 2021
}

All rights reserved. No part of this report may be used or reproduced in any manner whatsoever without written permission of the Institute except in the case of brief quotations embodied in critical articles and reviews. For more information write to:

West Africa Civil Society Institute (WACSI)

No. 9 Bingo Street, East Legon

P.O. Box AT 1956, Achimota

Accra, Ghana

Email : research@wacsi.org

Tel : +233 (0) 302550224

Cite this document as: Foyet, M. (2021). Youth Leadership and Governance in West Africa, WACSeries, Issue Paper, Vol. 7, Issue 3, West Africa Civil Society Institute, Accra, Ghana.

Disclaimer: The views expressed in this article are solely those of the author. WACSI does not take responsibility for the views expressed.

\section{LIST OF ACRONYMS}

$\begin{array}{ll}\text { AU } & \text { African Union } \\ \text { CSOs } & \text { Civil Society Organisations } \\ \text { ECOWAS } & \text { Economic Community of West African States } \\ \text { INGOs } & \text { International Non-Governmental Organisations } \\ \text { VET } & \text { Vocational Education and Trainings }\end{array}$




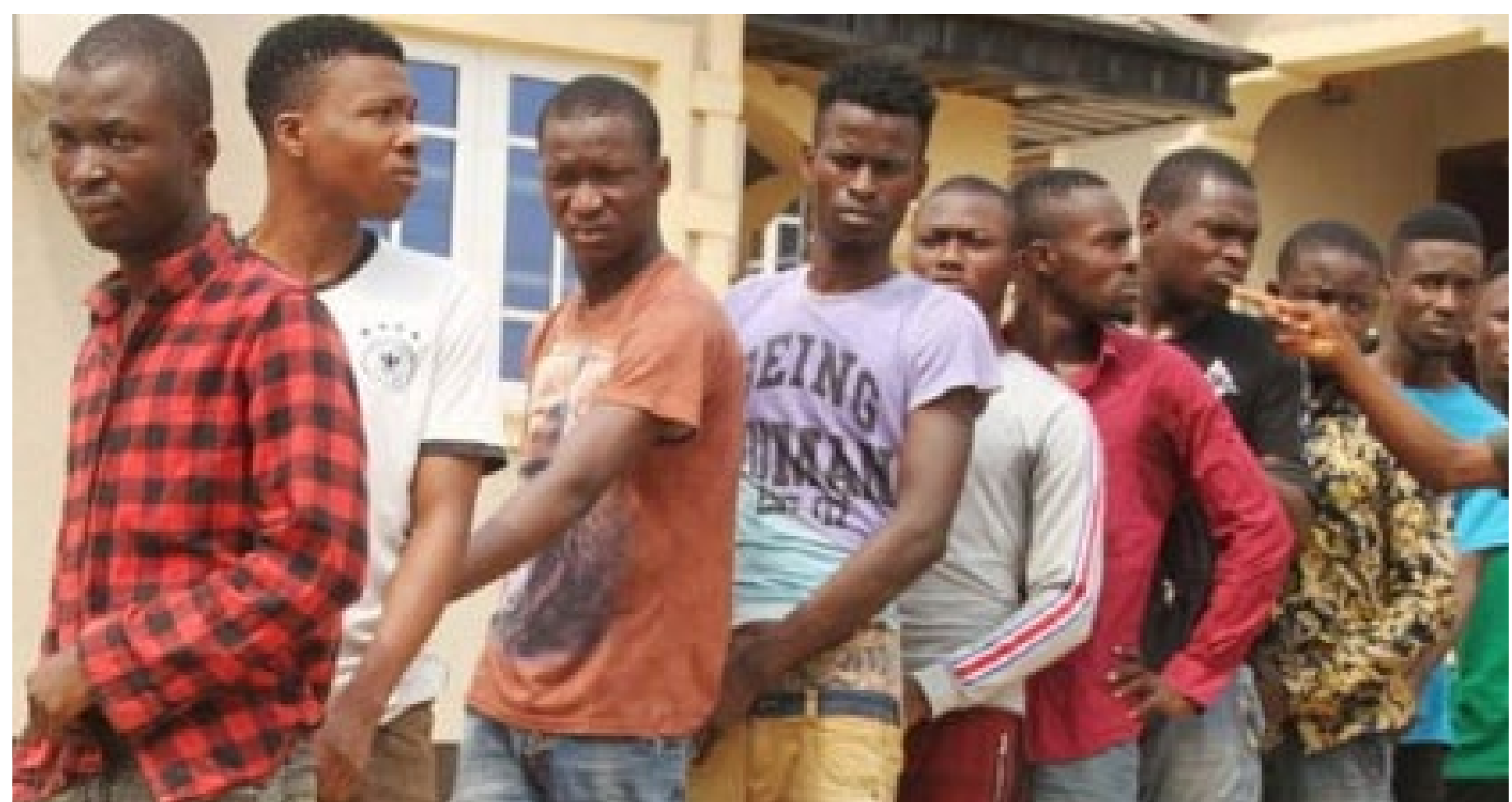

ABSTRACT

Are young people truly in a "waiting period"? As they turn into liabilities only when not recognised as assets, and become problems to solve only when not seen as solutions, does the youth realise that they matter now more than ever?

The problem with youth representation in governance is not just generational but also ideational, as the reality of weak institutions has a prevalence on the question of age. They are no longer driven by idealism but rather by materialism and opportunism. How can these youth be the agents of change when themselves require to be changed? In the following lines, factors favoring youth involvement in civil society in the region will be presented, whilst emphasising solutions by sector, notably through the academia, the private sector, the government and most importantly, the civil society itself.

Ultimately, innovation will be discussed as a tool to leverage in the political arena. It is noteworthy to stress that West Africa's large youth population can either spur innovation, creativity, and enterprise - or fuel instability and violence, as they face poverty, barriers to education, multiple forms of discrimination and limited employment prospects and opportunities. How policies, structures and processes are implemented in this regard will determine the prospects for current and future generations and economies.

\section{WHO ARE THE YOUTH?}

In its resolution 36/28 of 1981 (and for statistical purposes), the UN General Assembly endorsed the definition of "youth" as persons between the ages of 15 and 24 years. In a third of countries, according to the UNDP (2012), eligibility for the national parliament starts at 25 years or higher and it is common practice to refer to politicians as "young" if they are below 50 years of age.

Yet, for many people, turning 30 marks the end of youth. The general consensus is that youth lasts up to, and including the age of 29, and therefore, for the purpose of this paper, the author - without prejudice to any other operational, socio-cultural, institutional, economic or political definition and nuances of the term "youth", defines the latter as persons between the ages of 15 and 30 years. 


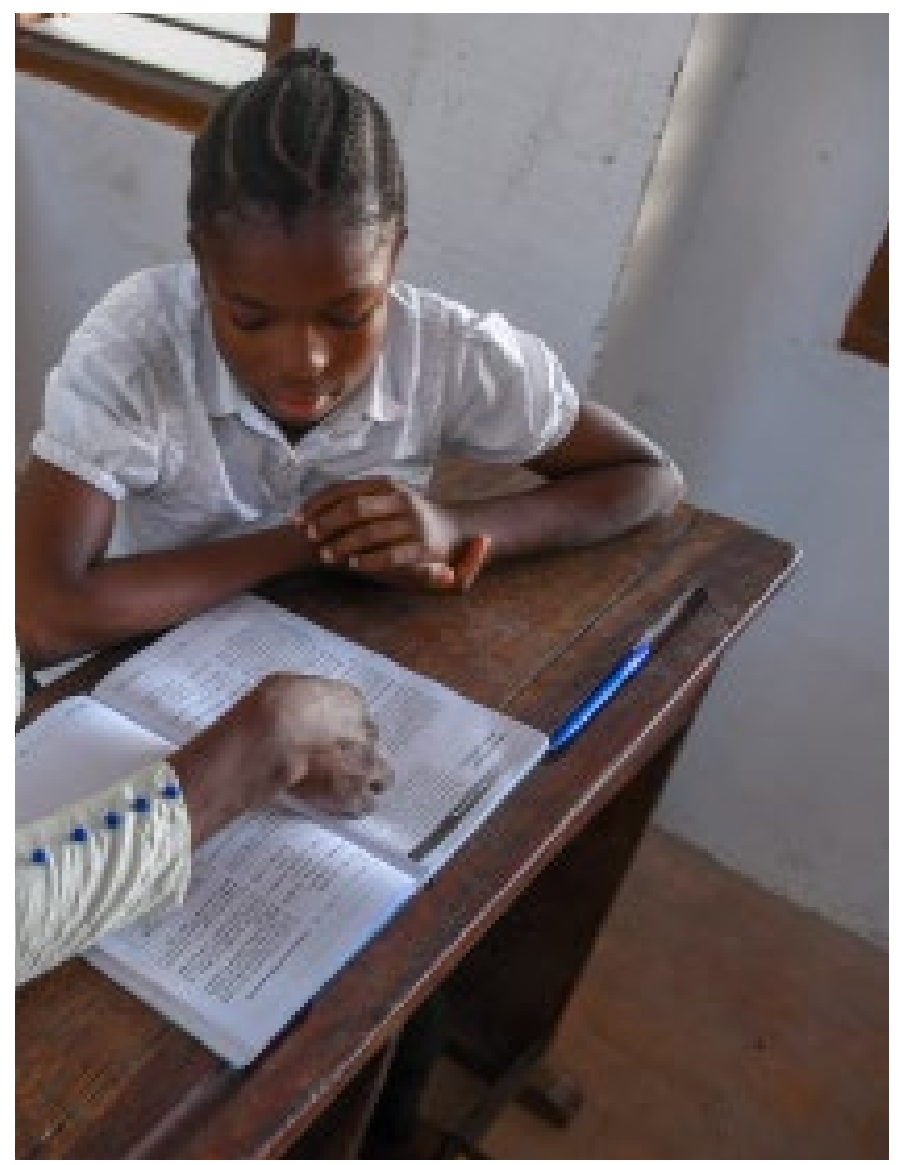

\section{Introduction}
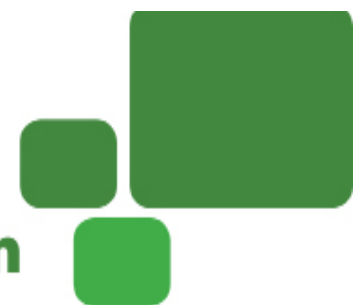

Are young people truly in a "waiting period"? As they turn into liabilities only when not recognised as assets, and become problems to solve only when not seen as solutions, does the youth realise that they matter now more than ever? The post-Arab spring has seen many youths in Africa remain politically and socially active through movements instead of engaging in political parties. Traditionally, the youth in Africa's western wing are this active in universities (when allowed) but very often disenchanted with institutional political processes. Opportunities for youth to engage in governance and participate in policy development depend largely on the political, economic and cultural contexts where social norms in many parts of the region (UNDP, 2012) result in multiple forms of discrimination against both young people and women at mid-level and decision-making positions.

Evenly, unemployment within the youth bracket makes them vulnerable to corrupt practices. It also serves as a powerful catalyst for joining revolutions as illustrated by
fruitfuluprisingsintheGambia(2016\#GambiaHasDecided), Nigeria (2015 \#NotTooYoungToRun Bill), Senegal and Burkina Faso (2011 Y'en a marre and Balai citoyen), South Africa (2016 \#FeesMustFall), and Sudan (2018 \#JustFallThat'sAll, "Minbar Chat" and "Bread Riots"); or mutinies as depict aberrant cases in Ivory Coast (2002), Guinea Bissau (1997), Sierra Leone (1991) and Liberia (1989).

Youth-led organisations are among the many movements youth in Africa have traditionally remained politically active in (Kadaga, 2016). In West Africa, youth-led civil society organisations (CSOs) (largely devised and implemented by young people) are mainly surviving rather than thriving (Restless Development, 2015). Because the space within which youth operate is political and politicised, they interact with and adapt to the regime in ways that allow them to survive. The politics of survival lead them to give a different legal status to their initiatives or to adopt an "ideological neutrality" that demands to invest in "strictly" social, economic, or cultural issues, over political issues. In the increasingly ideologically polarised West African society, it has been strategic for some youth to maintain that "ideological neutrality" to be able to better navigate differences and garner needed support and possible human and financial resources for their causes. Otherwise, many of the youth-led CSOs, including student unions go up for sale to the highest bidder (Kanyako, 2011).

The issue of limited or short-term funding puts most of these initiatives at the mercy of its landscape. This highly restricts and prohibits their institutional development as they become dependent on donor funding as they turn strategy-takers instead of strategy-makers. Fragile resourcing has led to skills gaps within these youthled CSOs (fundraising and resourcing management, partnerships, fluid volunteering scheme and staff bases and knowledge management).

The problem with youth representation in governance is not just generational but ideational, as the reality of weak institutions has a prevalence on the question of age. They are no longer driven by idealism but materialism and opportunism. The issue of attribution is on the menu as leadership is not decentralised and strategic opportunities are shared only among the executives, excluding the main human capital that constitute the bone of these structures. Talent tends to be linked to individuals rather than institutionalised (Kanyako, 2011). Most often than not only founders, co-founders or managing directors are found attending leadership fellowships, capacity building programmes, or conferences. But how do you 
implement what has been acquired if the eyes and the ears (volunteers, janitors and other "unimportant" staff) of the organisation are not given the respect they deserve?

The neglected (minor staff) are powerful resources to tap in as they often hold critical information and unsuspected and unexpected skills. The greatest tragedy that has befallen West Africa is that many of the youth who constituted the fulcrum for change have shed their idealism to become political hirelings, using the platform of youth organisations to give awards to business magnates and politicians (Hanna \& Hanna, 2009).

They have become tools, surrogates, and hangers of the elite. Some of them have become pure mainstream (status quo) players. How can these youth be the agents of change when themselves require to be changed? In the following lines, factors favouring youth involvement in civil society, public policies and governance in the region will be presented, whilst emphasising solutions by sector, notably from the academia, the private sector, and most importantly, the civil society itself. Ultimately, innovation will be discussed as a tool to leverage in the political arena.

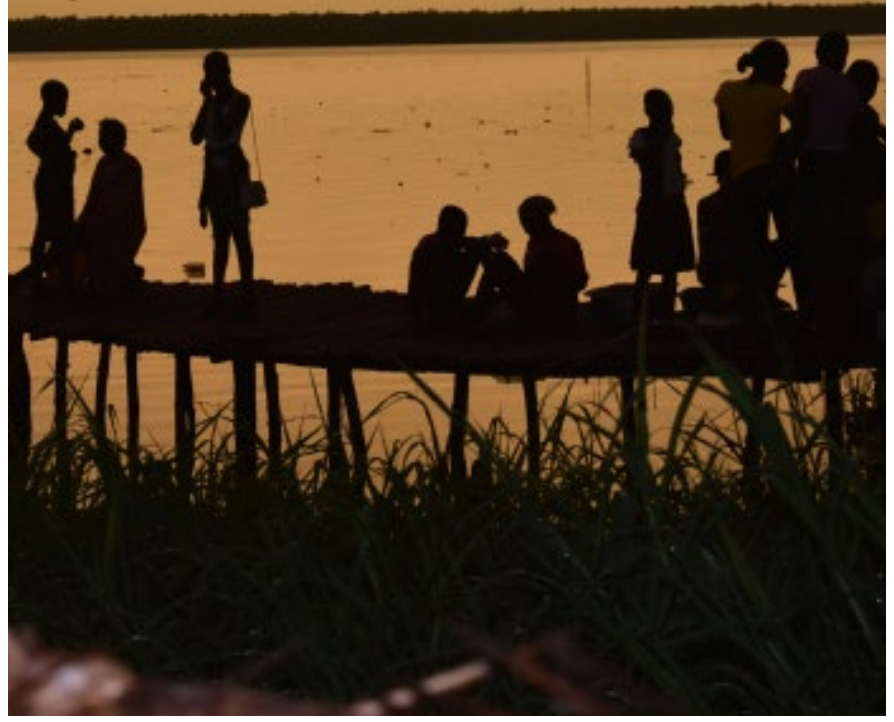

\section{I- The Status of Youth Leadership in West Africa}

As late Kofi Annan stated, "any society who does not succeed in tapping into the energy of its youth will be left behind". If Africa's greatest resource is its youthful population, then through their active and full participation, Africans can surmount the difficulties that lie ahead. Despite the numerous attempts [African Youth Charter (AYC), Youth Decade Plan (YDP), Agenda 2063, Malabo Decision on Youth Empowerment, among others] of its youth division, the African Union (AU) as a regional body does not have the power to implement or enforce youth policies on its member states, on which successful domestication and implementation of $\mathrm{AU}$ policies is dependent (AU, 2002). This remains a key challenge for the effectiveness of frameworks adopted by the $A U$ Assembly and welcomed by member states (AU, 2002). The proposed youth policies are not legally binding, and countries can therefore hide behind sovereignty when called into question.

In parallel, the Economic Community of West African States (ECOWAS) has equally originated several initiatives such as the Youth Entrepreneurship and Empowerment Programme (YEEP), Youth and Sports Development Centre (YSDC), youth leadership development in energy (ECOW-GEN). The impact of these projects, including both agency's programmes for young professionals, is yet to be measured.

On one hand, civil society could have a role to play in monitoring the implementation of these continental and regional youth policy instruments. However, the key issue with our civil society is funding. The nature and type of funding they receive influences the scope and extent of their role in ensuring impact. Moreover, the environment they operate in will guide their views on the issues at stake. So, if well-funded and operating in democratic setups, civil society can play a huge role in assessing these regional youth policy instruments. Since he who plays the piper dictates the tune, the questions would thus be: who should fund them (supply driven agenda vs demand driven agenda) and how should they be funded? Who should create the environment and to what extend are institutions willing to incorporate the views of civil society (Akouyu, 2020)? 
Level 1 is the lowest point. The youth, used as political thugs, are manipulated as they simply do what the powerful elders ask to be done. Level 2 is grandiose decoration, as the youth participate in events simply by entertaining the powerful. They merely serve as ornament in an activity in which they have no concrete influence in terms of what happens, why it happens and how it happens. Level 3 is pure tokenism, as the youth are given a chance to say what they think or feel about events and issues, but with significant restrictions on what they may possibly say and how they may say it. Level 4 translates into informed assignments. The commanding decides on what it is to be, but allows the youth to offer their services and express views which the decision makers respect (without necessarily changing the key decisions). At level 5 , consultation is introduced.

The influential still decides on strategies and generally runs the show, but consults the youth and their views are respected as the influential remains in control of what happens. At level 6, is witnessed controlled power of initiative. The authority initiates plans and ideas but involves the youth in decision-making, planning and implementation of the ideas. At level 7, youth is given full power to lead and initiate action while the decisionmakers are present. At level 8 , the youth and the elders share decision-making. It goes as far as entrusting the youth to handle affairs in the absence of decision makers: the young person becomes as a decision maker.

The "World Programme of Action for Youth for 2000 and Beyond" also touched upon the importance of youth participation in decision-making, but did not offer concrete interventions at the time (UNDP, 2012). This is where civil society should and could have played a role as concrete and strong lobbying actions are immediately needed - during and after events such as the world Programme of Action for Youth for 2000 and Beyond - for results to follow speeches and promises.

The topic of youth leadership requires to be seen through a new lens. We need to change the approach that has been in place so far in harnessing youth participation in the region. How do we go over recognising they are both the greatest assets of a nation as well as its daunting challenge and break away from damaging stereotypes of youth and patronising sentiments towards them? How do we reach Roger Hart's level 8 where youth are sharing the decision-making power with elders? How do we refrain from leaving them out of processes that shape their futures? How to ignite authorities' willingness to change?

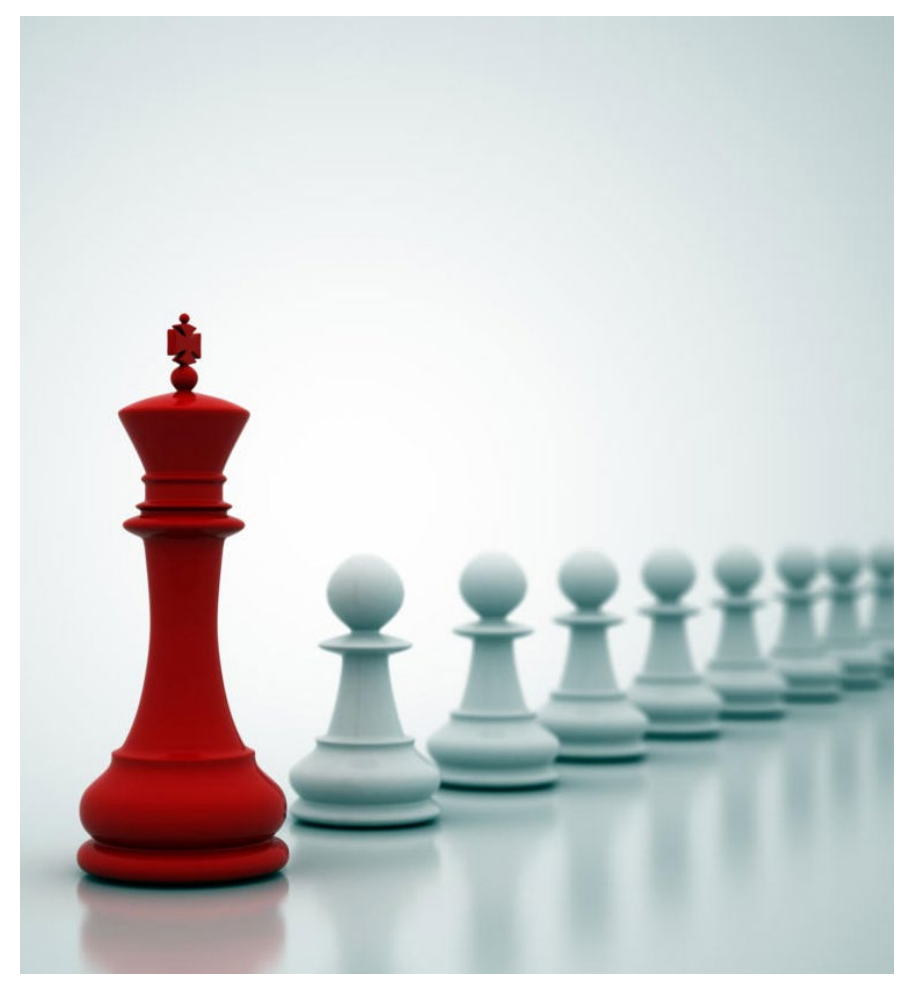

These are not the questions to ask as answers to these have been made available.

The key query is when? When do we truly and confidently get to act these reforms? A good way to go about it would accordingly be to entrust the youth with that task so as to benefit from their energy, exclusive range of knowledge about youth issues and unique perspectives to achieve sustainably developed and renewed societies.

As Owonikoko Olusola rightly said in his article "Political Moral Hazard: Another Reason to Fight",

"Let us not say any longer that
we are leaders of tomorrow. This
statement has turned out to be a
cheap bargain to trick young people
out of their responsibilities. We are
the leaders of today. Here is a fact:
over $60 \%$ of Nigerians are below
the age of 35. And they are truly
the custodians of posterity. If this
statistics and fact do not mean they
should be actively taking decisions
today, then nothing else will make
sense (Owonikoko, 2020)."




\section{II- The Role of Academia, the Private Sector, Civil Society and Governments in Increasing Youth Participation in Governance}

The aforementioned questions necessitate responses; urgent ones at that. It behooves on different sector players in West Africa's socio-political and economic systems to contribute in finding answers to these questions, and of course, with youths at the heart of their response strategies. This section attempts to explore possible response strategies different sector players - the academia, private sector and civil society - could enforce in an attempt to engineer a process that will enable key players to reach for Harts' levels 8.

\subsection{The Academia}

Universities can partner with institutions in different industries to create internship programmes which are tailored at meeting the current needs of the job market. This will empower young people with the skills needed to be leaders in different sectors in which theses internships are created. The same goes with compulsory national Service programmes, demonstrated in Nigeria and Ghana for example, aimed at offering the youth opportunities to participate in military activities, or any other industry of their choice. These national schemes can also be imposed by governments on every organisation and every kind of educational facility [vocational education and training (VET), universities] established on the national territory in order to facilitate the process of youth engagement and capacity building.

Civic engagement ${ }^{1}$ and politics are interconnected and the first definitely has great potential in leading to the latter. Civic engagement through national service encompasses a broad range of activities including community service (volunteer and mandated), political involvement (campaigns, government projects on the field), environmental service, several teaching programs, and military service (Youniss et al., 2002). Participating in such activities significantly enhances the transition from simple youth to adulthood with purpose, setting the stage for the next generation to become active and contributing citizens (Youniss et al., 2002).

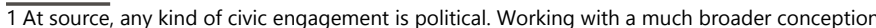
of young people (including even those who have not reached "the voting age"), the concept of participation in relation to the wider notion of "democratic citizenship" refers to the broader participation in relation to the wider notion of "democratic citizenship" refers to the broader
and more regular involvement in the public decisions within one's community (not one age group, or one type of gender). Therefore, the academia, the private sector and CSOs contribute to the normalisation of democratic citizenship by multiplying actions that are as inclusive as multilaterally possible.

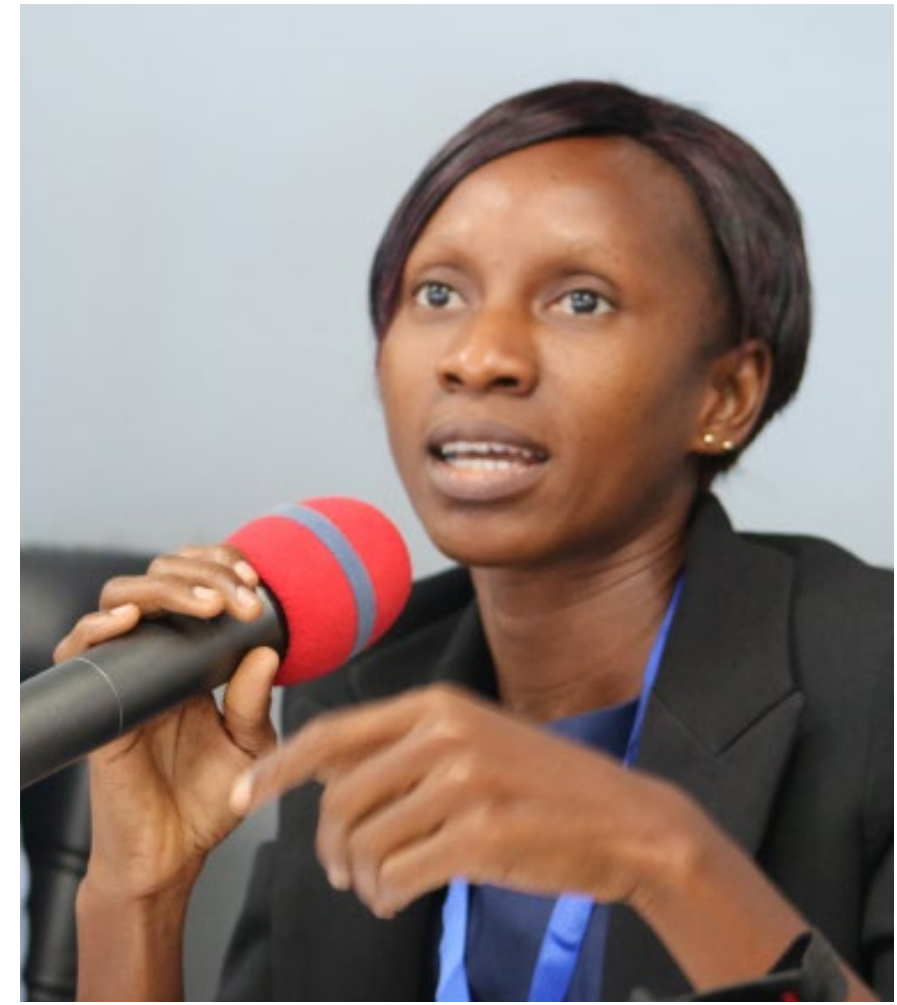

The normalisation of student and youth councils in universities and communities to allow keen youth to create and run clubs in order to stimulate youth participation and leadership has helped move a step forward. We can however leverage this practice by strengthening and streamlining it to mainstream governance processes whereby student leaders can be earmarked and given leadership positions at higher governance levels in society - an example is Okudzeto Ablakwa, former deputy minister of education in Ghana and now an MP.

Such councils can be used to develop a stronger culture of dialogue to better influence political, economic, and social leadership. They are particularly suitable as they enhance capacities of members to articulate, effectively communicate and persuasively argue issues that affect them as active individuals and engaged citizens. Special attention can be given to reinforcing the role of young women and physically challenged youth in leadership. This exists in many universities - I want to believe.

In partnership with the government, the civil society and academia can be explored to back development of a local governance game to engage youth both online and onsite, drawing on a similar exercise as Senegal (Senegalese Next Generation of Leaders), Tunisia's 'DemocraTweet', Kenyan web-based platform "voice in the hood", German online portal "Ich mache Politik" (I do politics), or even the 'DemoCrazy' movement. The internet can be used to incorporate distance and e-learning so rural youth have access to leadership-focused educational and vocational training. 


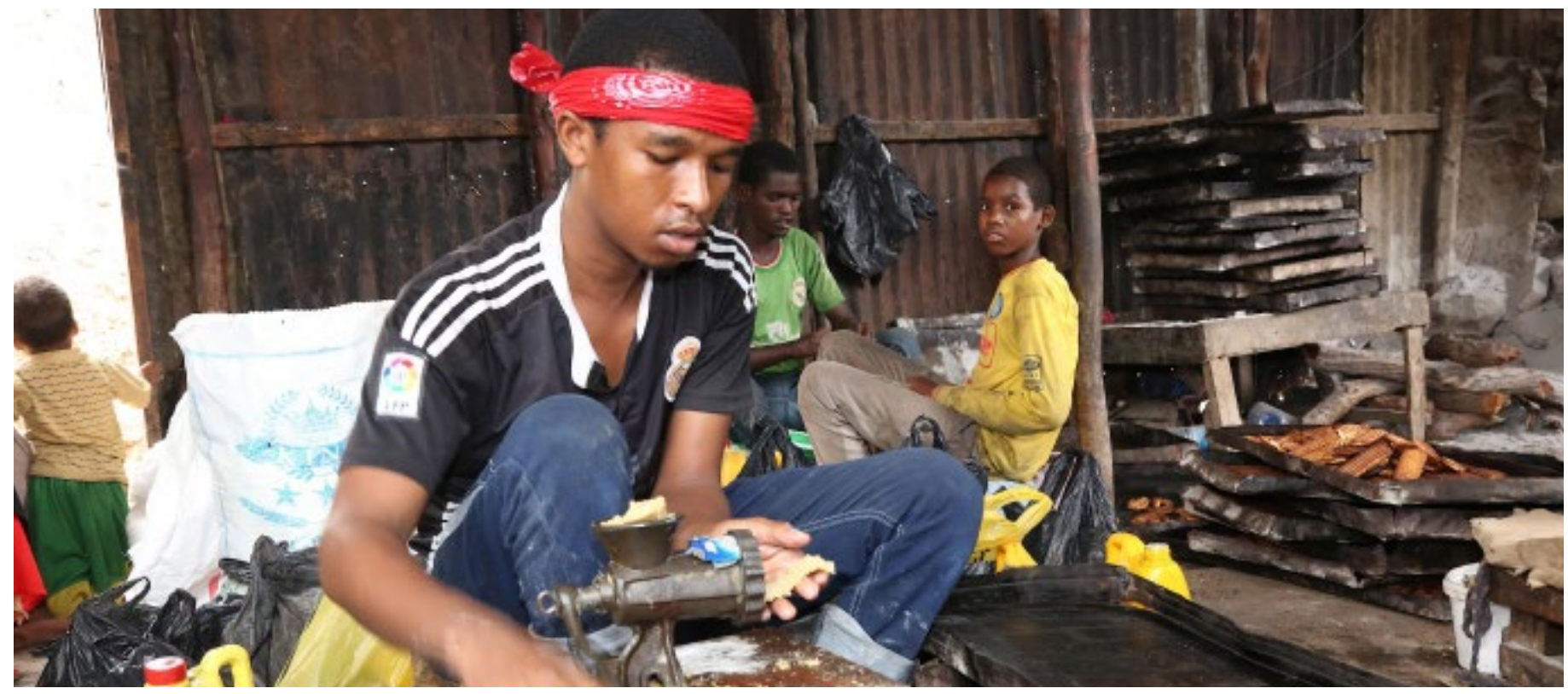

\subsection{The Private Sector}

The private sector, a major source of economic growth, employment, and investment, is a significant actor in enhancing youth development and nurturing youth leadership. National youth strategies are trending but suffer from weak funding. One of the significant ways the private sector could support would be by allocating more resources to youth and youth-led organisations.

Youth as a policy field cuts across various areas including employment, education, health, housing, mobility, justice, and sports, among others. With the replication of programs such as the Forum for Youth Investment (American), the private sector can support state policymakers with the tools to strengthen public policy affecting youth and to encourage youth participation in that process. Some of these tools can be defined as follows:

a. Special product teams or governmental agencies: Just as private firms routinely set up special product teams with the focused task of coordinating the work of various divisions to design, produce and market a new product, governments can establish independent agencies that could work hand in hand with private firms to push the youth agenda forward. For instance, in Benin, Patrice Talon's government of rupture has established specialised agencies such as the agency for the development of youth entrepreneurship (ADEJ). To overcome the expensive and less sustainable problem of lack of relevant skills, private sector companies operating in West Africa can bridge the education gap of the national youth work force through apprenticeships and trainee programmes.
Furthermore, they can work with training institutions and universities to develop courses tailored to their workforce needs. The private sector, which has equally been interested in investing in innovation, can apply that principle via tailored youth leadership hackathons, what we can simply call: Youthathons!

b. The "Children's Cabinets" movement can be created to better coordinate a wide array of youth services and programmes, by assisting states in developing collaborative governance structures that promote coordinating services for children and youth across state agencies and evaluate, coordinate, and improve the myriad of youth programmes. Providing new and alternative opportunities to contribute in meaningful ways to the youth's identity (experiences beneficial for work, education, and social relationships), allow the youth to participate and serve in ways not always provided by other contexts and activities.

Increasingly private institutions are looking at how they can introduce corporate social responsibility (CSR) for branding and attractivity purposes. A win-win solution is to apply a youth-focused lens, for example, by favouring youth-led small and medium enterprises. Under the CSR momentum and in collaboration with line ministries, organised and non-organised youth and CSOs, the private sector space can support by financing the development of a database of youth online groups in order to more systematically solicit input from youth groups on how to spur youth participation in the country's industrial and political life. 
Since research (UNDP, 2013) in post-broadcasting digital age has shown that younger voters felt more positive about democratic participation, actors in the private sector can sponsor a Youth Multimedia Civic Education Initiative aimed at reaching million young voters. Numerous young people can be trained to pilot leadership, entrepreneurship, and debate training across national territories. Such initiative can take the form of a series of TV, radio and webseries broadcasts developed in partnership with prominent Media houses that can inform by a baseline study on youth knowledge, attitudes and practices in the context of public affairs (UNDP, 2013). The vlogs, and the broad and pod casts can be designed as docu-series and entertaining stories oriented around the experiences of young people to inform them of their civic rights and responsibilities. These entertaining advertised spots can equally break down stereotypes that youth should refrain from active roles in public life.

Innovation camps for youth can be designed and sponsored by private industries. Just as the UN activities are simulated in Model United Nations (MUN) events, elections can me simulated in Model Electoral Processes (MEP) events, ministerial activities can be simulated - e.g. Model Energy Ministry (MEM), Model Interior Ministry (MIM), Model Defense Ministry (MODEM), and so on. National Debate and Public Speaking Olympiads can be sponsored on topics relevant to governance, industrial development, etc.

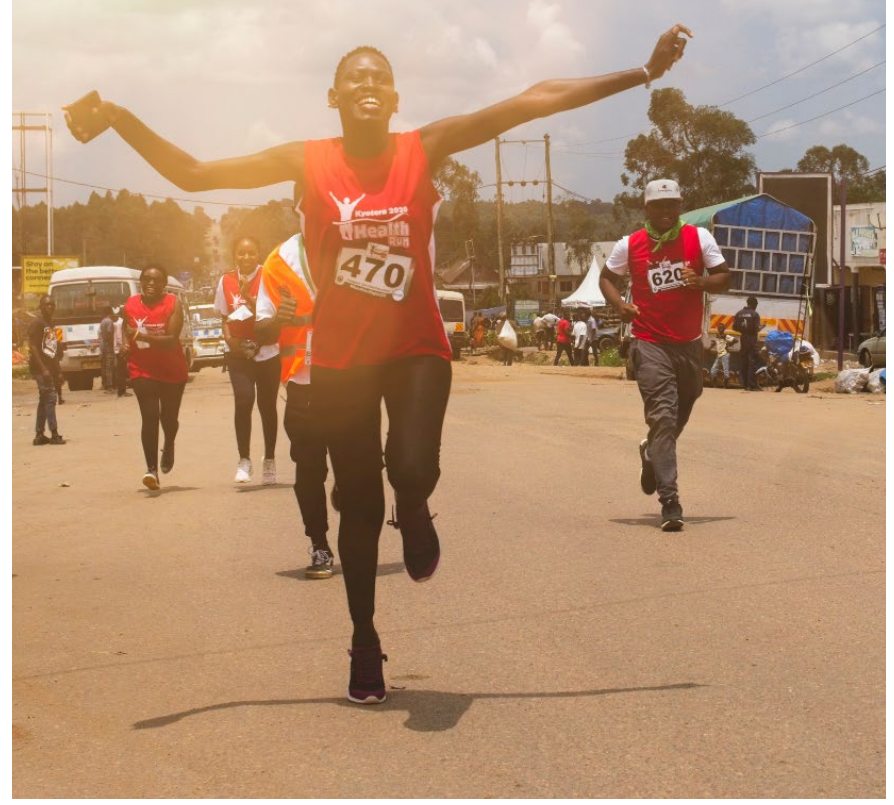

\subsection{By Civil Society}

As trust builders within and between societies, and as the "most efficient regulator of society" as avowed by the reputation they are preceded by, CSOs can play an important role in fostering bridges between governance and the youth. Civil society can contribute by producing information or ideas. It does not only encourage, but also facilitate open discourse and debates about youth leadership in West Africa. Distinct days such as the international day of democracy, international youth day or international woman day can be exploited to multiply outreach initiatives during which the youth and governing authorities will have roundtables. Such meetings can provide entry points and follow-up actions for youth organisations to engage with political parties on policy definition (Gyimah-Brempong \& Kimenyi, 2013).

CSOs can enhance learning and information-sharing within a nation's youth sector by stimulating conditions that lead to a greater integration of youth at the governance level, pushing for social and political change through strong and persevering campaigns. They can dissuade authorities from accepting the discrimination against youth at the governance level and build a social capital through strategic media such as twitter. In this regard, CSOs can learn from recent avant-garde events in the political sphere. Without a party or much funding, and with a groundswell in youth support, Kais Saied of Tunisia won the election. In Cameroon, Maurice Kamto has entrusted the youth with many strategic positions in his party and this has been demonstrated by their presence at the forefront of events, both nationally and in the diaspora, at TV shows and on social media. Passions can be (re)generated and transnational constituencies contested and mobilised for the purpose of involving the youth at governance level.

We do not need to wait for the next western-inspired \#MeToo kind of petition to launch a similar \#YouthToo movement to promote greater inclusion of youth in the West African political arena.

Technologies allow young people to be at the forefront of confronting electoral fraud (IDEA, 2018). By using digital platforms for youth engagement in macrolevel reforms, we make them enormously powerful tools as they can bring alive ubiquitous images and make them accessible to a myriad of people. This can in turn prompt for a shift from micro-targeting to an all-inclusive participation (submission of self-designed projects, voting-based selection, participatory budgeting, mobilised implementation and voluntarily monitoring of outcomes and impact). 
CSOs can partner with ministries of social welfare, youth or women as greater national attention to youth issues is evident in such ministry. As done in Mongolia, CSOs in West Africa can recommend for a revision of civic education curricula to better appeal to youth and trained young journalists. For instance, in Nigeria, the United Nation's Development Programme (UNDP) has supported youth based CSO coalition to actively participate in the constitution review process, including submission of memorandum to the constitution review committees (UNDP, 2012) of the National Assembly.

\subsection{What about the Government?}

As the primary facilitators of an enabling environment for the youth to be involved in governance, the government clearly plays a pivotal role in the successful implementation of measures intended to increase youth participation in governance. Shifting to e-governance (WPAY, 2006) is a concrete way to engage more youth in public leadership as it facilitates the accessibility to government services, allows greater public access to information, offers a wide scope of possibilities to engage in political activities (online forums, electronic petitions, political blogs, etc.) and makes governments more accountable to citizens.

By enhancing the government's ability to request, receive and incorporate feedback from constituents, policy measures can be better tailored to meet youth's expectations. E-governments can easily collect, monitor, and use data to improve government interaction with the youth. Essential services for young people can be delivered using mobile technology as a job search tool, providing skills training and job matching, promoting positive lifestyle choices and behavioural change, and introducing smart commute interventions to securitise strategic layers (public transport, health, shelter, food, etc.).

Moreover, as high turn-over and lack of institutional mechanisms present key challenges for inter-ministerial coordination on youth affairs, inter-institutional coordination, both across different ministries and between the central and subnational levels of government, is essential to ensure a clear division of roles and responsibilities and align the objectives set out in national youth strategies and sectoral. This can be done by establishing a well-resourced secretariat in the ministry responsible for coordinating youth affairs to avoid that this task will be added on top of the existing responsibilities exercised by civil servants. This secretariat will establish inter-ministerial committees (or working groups for specific topics) and designate focal persons for youth affairs in all ministries and other government bodies. Each working group for specific topics will be chaired by youth focal points of ministries with corresponding portfolios. And inter-ministerial committees will include focal points and members of the ministry in charge of youth affairs. Clear action plans for each level of government (national, regional, and local) and thus each focal point will be developed (Restless Development, 2014). Engagement and coordination with CSOs, youth networks and other partners can now be improved, and the secretariat will design a joint action plan to clarify mandates, ensure ownership and monitor the work of the coordination mechanism based on clear objectives and targets.

Finally, templates and joint standards can be used to promote a common approach to monitoring and evaluating the outcomes of government action for young people. Since most prime ministers in West Africa appear to play a passive role in governance, to save cost, they can be assigned the portfolio of Intergovernmental Affairs and Youth as done in Canada - supported by a Prime Minister's Youth Council (PMYC) which could serve as secretariat or advisory body on matters pertaining to the nation's youth.

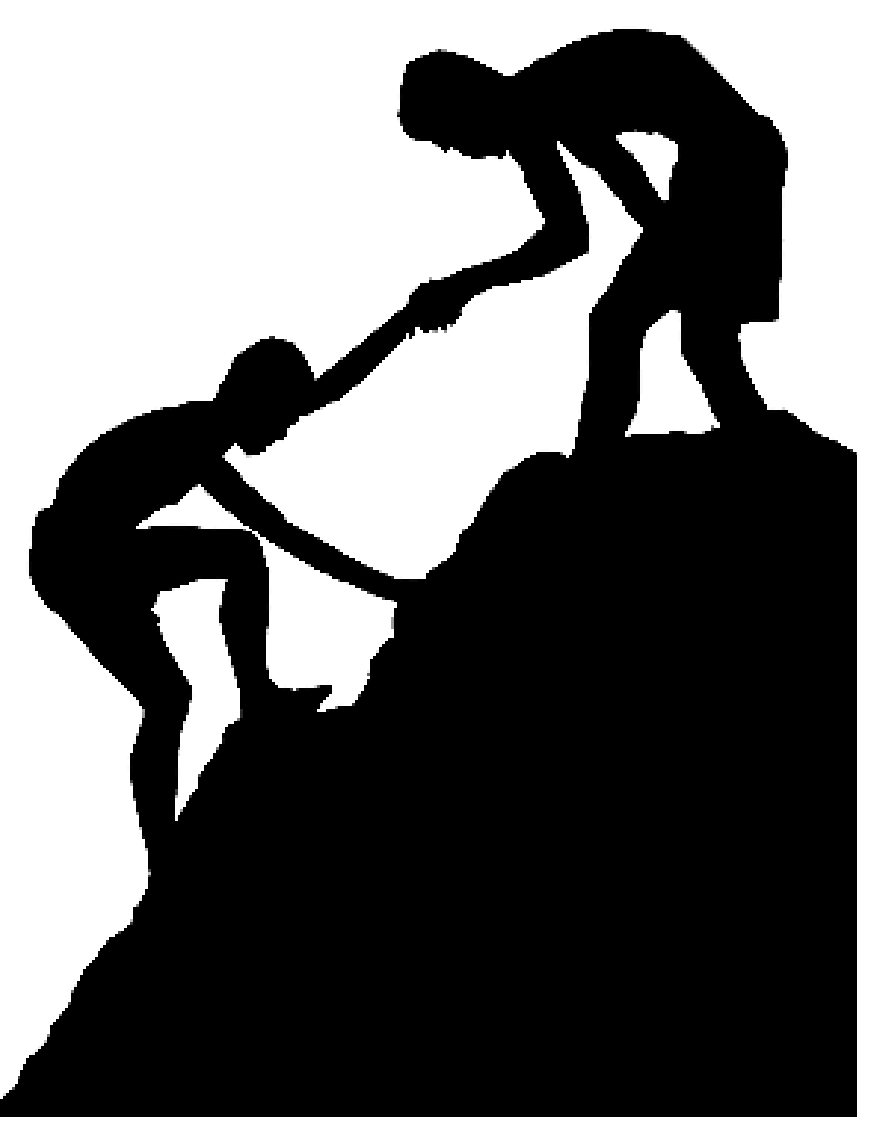


There is a direct link between the plight of West African youth and the prevailing governance systems in the region. It is essential to convince the old political class that youth empowerment and inclusion in governance processes is a sine qua non for overall national development, peace, and security. The demographic picture of youth makes it patently evident that engaging youth fully in development is not a matter of choice, but rather an imperative for national development.

\section{III- Leveraging Innovation in the Governance Arena}

\subsection{Establishing national youth observatories}

Civil society can push for the establishment of National Youth Observatories, as done in different countries in West Africa under different appellations: Youth Empowerment Agency, National Youth Commission, etc. Viewed through the lenses of the participatory paradigm, this increases the chances for social change considerably, as people become the agents of their own society (Peisker, 2011). Such a framework, at the national and regional levels, would serve to ensure that proper sanctions are applied where there are implementation failures. Training can be provided to youth-led advocacy organisations on governance assessments.

This will aid in developing an indicator framework on degrees of youth participation and the mainstreaming of youth issues-covering processes such as debates between political parties, national reconciliation efforts and the creation of a constitution and political party development for example. Youth groups will learn to collect data under the Youth and Political Participation framework, and disseminate it to policy makers and the general public. Moreover, assessment tools can be developed to examine how adequately national policies respond to youth concerns.

These youth observatories, run by young people, can establish a concrete monitoring and evaluation mechanism with detailed information on how to report on the progress made in achieving set objectives. Data to measure progress could be disaggregated by ethnicity, gender, disability and socio-economic background. Observatories will also prepare, coordinate, and initiate surveys, recommendations, analyses, studies, and reports on the different aspects of the situation of young people in each West African nation. After which one-pagers recommendations will be put forward for submission to the government.
Moreover, observatories will be mandated to conduct vetting before appointed leaders occupy public offices and social audits automatically during and immediately after the latter's mandate ${ }^{2}$; incubate youth-led social impact projects and connect, equip and inspire young people to bolden up and build on existing youth programs and sustainably re-appropriate them in order to avoid wasting resources in analogous programs. Also, ideas can be pitched, and best propositions can be considered to proceed to parliament and defended by idea champions. Finally, observatories can serve as a dedicated body composed of youth-led associations and youth wings of political parties.

\subsection{Rethinking pre-electoral strategy for youth engagement}

A youth agenda on political participation and youth interparty forums can also be developed ahead of elections as has been done in Nigeria ahead of the 2015 election (UNDP, 2012). Such initiatives will be used by youth members across party lines to expand the frontiers for youth political participation by coming together and deliberating on issues of common interest. National Youth Parliaments can be established, as done in Namibia, to empower active citizens at both local and national level and provide an opportunity for youth to contribute to the framing of national policy through direct dialogue with parliamentarians (UN, 2006).

\subsection{Gaining lifelong civic knowledge}

To ensure responsible governance, central is the need to develop a common understanding of the role of public institutions. Promoting early acquisition of valuable life skills and developing a healthy self-esteem are a must and inspiring trust is the vital core of any change initiative. Inculcating a culture of participation at an early age makes it more likely that young people will continue to be active citizens as they grow older and this pattern of behaviour becomes a lifestyle (Okombo, 2011). Indisputably, as individual and collective values and principles are fundamental to appropriate political practices, perhaps the most significant action civil society must take would be urging for such values to be inculcated early on and perpetuated throughout the educative and corporate systems in what young people to adults are exposed to. As teaching is the culmination of what is seen, felt, and heard, kids can be taught skill sets for making good choices, for getting along well with others, and for managing time wisely (Waller et al., 2016).

2 The list of positions for which candidates should be vetted and socially audited is long, but for purposes of focus, it includes the following obvious ones: ministers and deputies, governors and deputies, mayors and deputies, senators and members of the national assembly, ward representatives, executive committee members (i.e., members of the cabinets of governors, minresentatives, executive committee members (i.e., members of the cabinets of governors, min-
isters and the president), heads of state-owned institutions, and heads of decentralised local administrations. 


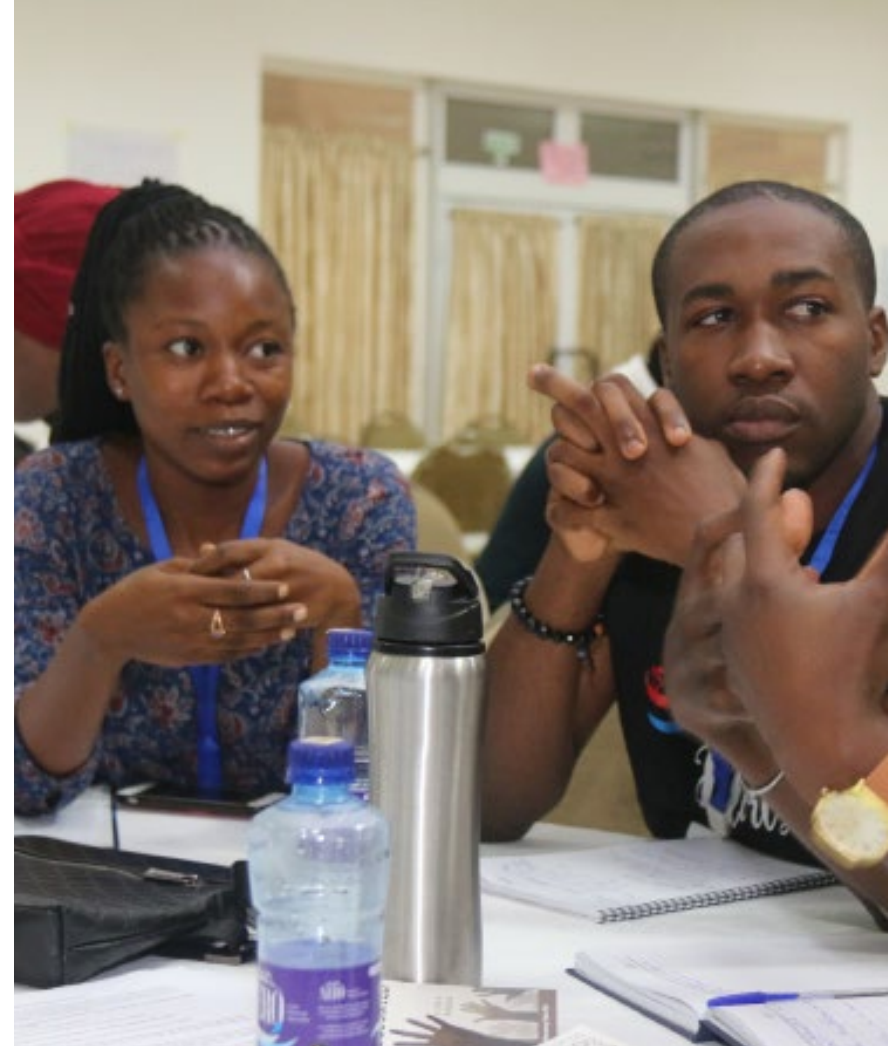

\subsection{Providing authentic opportunities for knowledge application}

In addition, authentic opportunities to apply these skills should be provided by giving students leadership opportunities in the classroom, in the school, and in the community. For this fundamental phase to succeed, we need teachers who can inspire trust, either through natural charisma or pedagogic training. Managers, leaders, teachers, and parents should identify new ways of educating youth about the future - shifting from what to learn to how to learn, focusing on the value of commitment rather than on what youth are committed to.

Enke's Trailblazers programme (South Africa), KIPP charter schools, Steiner-Waldorf or Sudbury school systems (Kenya, Namibia, Tanzania) and the Harlem Children's Zone are compelling cases that noncognitive competencies - Lerner's Five C's (competence, confidence, connection, character, caring), resilience, self-control, curiosity, conscientiousness, grit and growth mindset - more than academic skills [measured by the traditional intelligence quotient (IQ) test or standardised national exams] and sheer brainpower, are needed for fit leadership and success (Borghans et al., 2016).

Civil society actors can work in partnership with actors in the implementation of such models in Eastern and Southern Africa to study how to adapt these principles to the youth sector in West Africa. The dominance of EQ (emotional quotient) and SQ (social quotient) over IQ (intelligence quotient) are influencing and thus reshaping societal systems into systems that need to adopt open and flexible social norms. Adults should change from working for the youth to working with the youth (OECD, 2018) (O'Doherty et al., 2015) for example. Civil society actors and stakeholders mentioned so far need to be able to find the talents and voices of youth, engage their hearts, minds, bodies, and spirits, and optimise and unleash their potential (for roles such as communicators, negotiators, policy makers, power brokers, lobbyists, decision-makers, facilitators, overseers, institution builders, resources mobilisers, enablers, leaders).

\subsection{Adapting the youth-friendly governance system to the West African context}

A great starting point for the materialisation of the previous suggestion is to think towards the realisation of a youthfriendly governance system; the kind that is addressed by research, progressively reflected in academic curricula, and moved beyond governing officials and experts. In such a system, all actors - practitioners, CSOs, communities, municipal authorities, governing bodies - are committed to setting up mechanisms that protect the best interests of youth, respect youth views, prevent discrimination, ensure survival and maximum development of all youth.

The focus on the youth as whole is crucial to build healthier adults with stronger values for better societies. In a youth-friendly city, with an indivisible body of legal provisions, everything is inter-dependent as sectoral programmes, services and interventions can no longer run independently; all sectors converge to provide an integrated response to the indivisible demands of [youth] (Riggio, 2002).

In such a system, the multiplication of haphazard interventions and adoption of ad hoc projects is disregarded to the benefit of foundations laid by assessing needs and existing responses in order to gear up systems to respond to the nation's challenges from all perspectives. Once such mechanism is in place, governance goes at its best as minorities (youth, elderly, disabled, women) are fully integrated enough to fuel tension. Although this idea may sound, to many, too idealistic, or unrealistic for African settings, it is important to highlight that Seychelles, lead in child-friendly governance system in Africa (ECCE, 2011), has proven that child-friendly governance can successfully be implemented in Africa and essentially requires willingness of political authorities for the change-process to be triggered and implemented. 


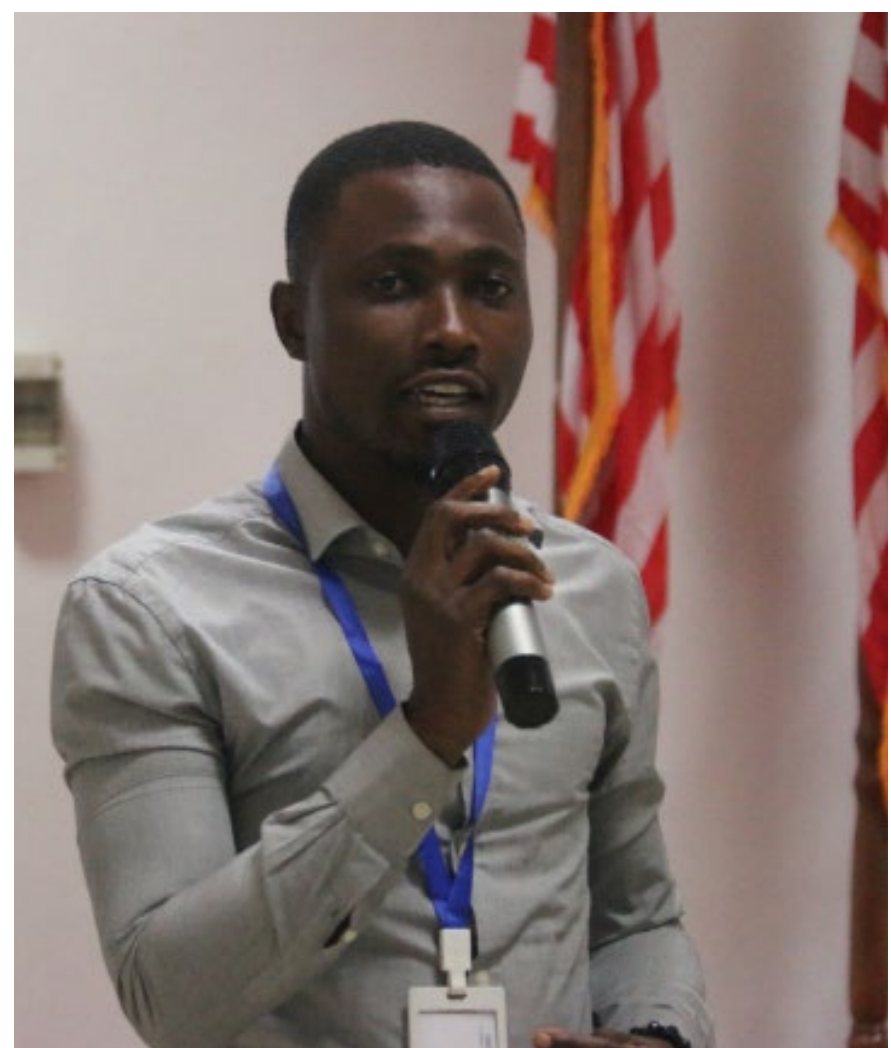

CSOs could study initiatives such as the West African Hip Hop Political Production of AURA's and its Extraordinary Stories of Poto-Poto Children or the Political Leadership Development Programme (PLDP) - most ambitious political leadership training effort currently offered in East-Africa - to design more creative civic solutions.

\subsection{Mainstream sports and cultural activities in governance processes: good old political buddies}

Another glowing way to mobilise for a healthier inclusion of youth in governance and the fight against objectionable practices is the use of sports and cultural activities. The entertainment industry can play a very crucial role in the making of young people into becoming active and exemplary citizens. Other social activities such as birthdays, weddings, parties, and other ceremonial gatherings are opportunities to capitalise on.

Any activity susceptible to interest young people provide an immense occasion for political education and mobilisation. A mechanism can be put in place for the vulnerable and disadvantaged groups to receive support in making links to legal aid providers and support networks, as well as National Legal Aid Councils and related initiatives which aim to develop capacities to support youth empowerment for disadvantaged youth.

\section{Conclusion}

Youth leadership in West Africa has a better chance of thriving if embraced by competent and responsible youth, who unceasingly acquire and learn to use skills, knowledge, and attitudes that prepare them to face realities. They are informed and thoughtful, have an understanding and awareness of public and community issues, participate in communities through contributions to organisations working to address an array of political, cultural, religious, or social interests and beliefs. They equally have a grasp of history.

As the power of production has shifted from political and economic agendas and media corporations to the people, competent and responsible youth have the ability to think critically and unconventionally, obtain and produce information, create knowledge and highlight relevant issues, to engage in a dialogue with others with different perspectives and have an appreciation of moral and civic virtues. They are tolerant and genuinely are concerned for the rights and welfare of others and take social responsibility seriously as they involve in public speaking and problem solving. Most importantly, they have a strong faith in the capacity to make a difference.

Fostering an inclusive and active involvement of youth in governance is imperative and a smart investment in sustainable development and peace in West Africa. Identifying and addressing context-specific legal barriers to youth participation in governance, such as to facilitate the registration of youth-led organisations for example; adopting youth-friendly legal frameworks; or reviewing the stock of existing regulations to ensure that youthrelated objectives are advanced and sufficient capacities and resources for this purpose are mobilised are exemplary starters.

Accordingly, to overcome the specific challenges facing the youth in the civil sector, there needs to be reform of the civil society sector, and strategies need to be introduced to not only increase and sustain the flow of resources into youth-led or youth-focused organisations, but also regulate this flow in order to prevent mismanagement. 


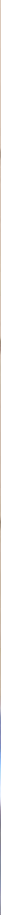

ECOWAS, just as the European Union, could launch a digital "YouthMetre" project as part of its efforts to use open data to drive youth participation in policy advocacy - an online dashboard that provides an accessible and engaging way to visualise data, providing indicators for all ECOWAS member states on a range of measures, including health and wellbeing, volunteering and political participation, cultural engagement and social inclusion among others. The confidence of the youth needs to be developed so they can engage in governance processes at a higher level and not just through social media.

The latter has limitations and much more attention needs to be focused on political education. Because social media is often used by opposing parties to fight each other, create political divisions or organise along sectarian or ethnic lines, we need to imperatively find ways to build bridges and avoid the tendency of using social media to engage in and disseminate hate speeches.
In as much as this widely recognised factor of change (technology) allows for efficiency, the issue of cyber insecurity remains, until further notice, a terrific reality. The youth needs to be educated about engaging ethically on media platforms so as to not only avoid being used to fuel tensions, but also to protect their integrity. Youth-led organisations can lead such initiatives on responsibility and self-regulation by bringing together active users to adopt ethical codes.

Africa's large youth population can either spur innovation, creativity, and enterprise - or fuel instability and violence, as they face poverty, barriers to education, multiple forms of discrimination and limited employment prospects and opportunities. How policies, structures and processes are implemented will determine whether their effects are positive or negative. 


\section{SOURCES AND BIBLIOGRAPHY}

Adewumi, F. (2007). The Challenge of Repositioning Civil Society for Responsive and Accountable Governance in Nigeria. In A. Babawale, An Agenda for a New Nigeria: The Imperative of Transformation. Lagos: Concept Publications Limited.

Akinyeye, Y. (2010). Nation-states and the Challenges of Regional Integration in West Africa: The Case of Nigeria. Karthala.

AU. (2002). Protocol Relating to the Establishment of the Peace and Security Council of the African Union. Addis Abbaba: African union.

Borghans et al. (2016). What grades and achievement tests measure. Proceedings of the National Academy of Sciences, 113(47),13354-13359.

British Council. (2015). Governance and Civil Society, SubSaharan Africa. Partners for Change.

Cook, K. (2001). Trust in Society. Russell Sage Foundation. Development Alternative. (2019). Towards a thriving, credible, and sustainable youth civil society. Development Alternative.

ECCE. (2011). The Seychelles Framework for Early Childhood Care \& Education (ECCE). Government of Seychelles.

Gyimah-Brempong , K., \& Kimenyi, M. S. (2013). Youth policy and the future of african development. Working Paper 9: Africa Growth Initiative.

Hanna, W., \& Hanna, J. (2009). Urban Dynamics in Black Africa: An Interdisciplinary Approach. New Jersey: Transaction Publishers, Rutgers.

Hart, R. (1992). Children's Participation from Tokenism to Citizenship. Florence: UNICEF Innocenti Research Centre. Hart, R. (2013). Children's participation: The theory and practice of involving young citizens in community development and environmental care. Routledge.

IDEA. (2018). Youth Participation in Political Processes. Stockholm: International Institute for Democracy and Electoral Assistance.

Kanyako, V. (2011). The check is not in the mail: How local civil-society organisations cope with funding volatility in postconflict Sierra Leone. Africa Today, 58(2), 3-16.

Misztal, B. (1996). Trust in Modern Societies: The Search for the Bases of Social Order. Cambridge: Polity Press.

O'Doherty et al. (2015). Strategies to Strengthen Youth Leadership and Youth Participation Opportunities in Central Appalachia. University of New Hampshire.
OECD. (2018). Seven Key Findings from the Youth Governance Survey. OECD and MENA.

Okombo et al. (2011). Challenging the rulers: A leadership model for good governance. East African Educational Publishers Ltd.

Owonikoko, O. (2020, October 17). Political Moral Hazard: Another Reason to Fight. Retrieved from https://medium. com/: https://medium.com/@owonikokoolusola/politicalmoral-hazard-another-reason-to-fight-72383d9e8bb9

Peisker, M. (2011). The Communication of Participation: An Exploratory Study of the Effects of Social Media on Social Change, . Bachelor Thesis in Marketing \& Management Communication.Restless Development. (2014). Youth Participation in Local Council Decision-Making in Sierra Leone: The successes and challenges of decentralised participatory governance from a youth perspective. Restless Development.

Restless Development. (2015). Nurturing Youth Leadership in the Global South: A Mapping of Strategies, Approaches, Challenges and Opportunities. Restless Development.

Riggio, E. (2002). Child friendly cities: good governance in the best interests of the child. Environment $\&$ Urbanisation, 14 (2), 45-58.

Sesay, A. (2014). African Governance Systems in the Pre and Post-Independence Periods: Enduring Lessons and Opportunities for Youth in Africa. Johannesburg: Mandela Institute for Development Studies.

UN. (2006). Youth in Africa: Participation of Youth as Partners in Peace and Development in Post-Conflict Countries: Report of the Expert Group Meeting. New York: United Nations.

UNDP. (2012). Enhancing Youth Political Participation throughout the Electoral Cycle (Fact Sheet) . New York: United Nations Development Programme.

UNDP. (2013). Enhancing Youth Participation throughout the electoral cycle. New York: United Nations Development Programme.

UN-Habitat. (2003). Young People in an Urbanising World. Habitat Debate, 9(2).

Waller et al. (2016). Mechanisms for inspiring action in South African Youth. African Evaluation Journal, 4(1), https://aejonline.org/index.php/aej/article/view/120.

WPAY. (2006). Guide to the Implementation of the World Programme of Action for Youth. New York: United Nations.

Youniss, J., Bales, S., Christmas-Best, V., \& Diver, M. (2002). Youth civic engagement in the twenty-first century. Journal of Research on Adolescence, 12(1), 121-14. 


\section{WACSI}

Strengthening Civil Society

(c) WACSI 2021 All Rights Reserved. 